\title{
Surgical experience of neurosurgical residents in Europe: an alarming trend
}

\author{
Asgeir Store Jakola ${ }^{1,2}$ (D) Thomas Skoglund ${ }^{1,2}$
}

Received: 15 March 2019 / Accepted: 20 March 2019 / Published online: 29 March 2019

(C) Springer-Verlag GmbH Austria, part of Springer Nature 2019

The study by Stienen and coworkers aim to establish the amount of procedures performed by European neurosurgical residents and explores the time trends concerning surgical training during residency. With respect to time trends, they specifically evaluate the caseload of residents before and after the European 48-h workweek restriction (2003/88/EC) [10]. To answer these questions, the authors created a survey that was distributed through the EANS network. The respondents had completed their training in the period 1976-2018, with more than $50 \%$ of respondents completed training in 2011 or later. In total, $72.5 \%$ of responders completed training after the introduction of the European work-hour restriction. The authors report the median independent procedures were 511, supervised procedures were 514 , and assisted procedures were 752. There was a clear negative time trend, with neurosurgeons certified earlier having performed more procedures. Specifically, certified neurosurgeons after the European work-hour restriction had performed less procedures than those certified before the restriction. The main limitation of the report is that their analyses are based upon answers from only 80 respondents, with a clear risk of recall bias that may be more pronounced with increased time since completed training. Also, the actual working hours may not be in accordance with the regulations since we all know colleagues putting in significantly more hours than the regulatory upper limit

This article is part of the Topical Collection on Neurosurgery Training

Asgeir Store Jakola

Jakola.asgeir@gu.se

Thomas Skoglund

thomas.skoglund@vgregion.se

1 Department of Neurosurgery, Sahlgrenska University Hospital, Blå Stråket 5, 41345 Gothenburg, Sweden

2 Institute of Neuroscience and Physiology, University of Gothenburg, Sahlgrenska Academy, Gothenburg, Sweden (although often not reported). Still, the data support an association between the work-hour restriction and a reduction in caseload. Finally, the authors also rightfully conclude that this survey does not answer the question of training quality and that numerous factors may counteract the reduction in caseload for patient outcome.

Historically, the amount of working hours invested per week had no limit. For instance, the residency program that Dandy completed with Halsted consisted of 24 h daily, every day for 50 weeks - allowing 2 weeks of vacation [8]. When looking back three decades ago, surgeons reported working weeks of $100 \mathrm{~h}$ and doing 24-h shifts every other day, but still a remarkable reduction from the residency model of Halsted [1]. Now, the American system with the Accreditation Council for Graduate Medical Education (ACGME), 80$\mathrm{h}$ week restriction has been much debated [1].

In light of this, the 48-h work-hour restriction seems restrictive and the authors rightfully attempt to evaluate its effect since this has several implications for patient care in the short term and education in the longer term. For instance:

- Increased patient handoffs with high demands for effective and structured reporting with a team-based approach to management where all patients receive the same attention and this requires that we are not only engaged in our own patients [2].

- Less procedural exposure during residency logically requires either improved teaching output per case or longer/individualized residency programs. Individualization could mean a milestone-based system rather than a system based upon time and rotations.

- A residency that does no longer provide a common ground (e.g., too early sub-specialization to fit the department needs) may hamper mobility and create neurosurgical silos without significant exchange of ideas. Lack of common ground will cause increased fragmentation of responsibility and care - and presumably, also interfere with the team-based approach mentioned above [7]. 
The presumed negative effect of work-hour restriction on surgical training needs to be balanced against the evidence in support of increased fatigue, increased error rates, and impaired cognitive function that long-working hours and especially night shifts may cause [3, 4]. Acute sleep deprivation also reduces reaction time and accuracy [12] It has been observed that less extensive work hours caused a decrease in attention failures in the ICU setting [5] and no apparent deterioration in outcome have been observed following the ACGME restriction when evaluated in a broad range of clinical specialties $[6,11]$. We are also not working in isolation, and it is not solely the surgical handcraft that influences surgical outcome. When looking at historical data, patient outcome following neurosurgical procedures in modern neurosurgical practice has improved despite an obvious reduction in work hours and presumably also caseload [9]. This improvement can hardly be attributed to more alert neurosurgical residents, but it is probably multifactorial through progress in imaging, patient selection, surgical instruments, intraoperative visualization, neuro-anesthesia, and neuro-intensive case. These improvements may have offset the effect of reduced surgical training for patient outcomes. Still, our collective experience tells us that surgical hand skills are best taught in the operating room.

This preliminary report is not suited to draw any conclusions concerning neither the amount of working hours or specific procedural exposure needed during neurosurgical residency [10]. Nevertheless, to get the best possible overview of current status in Europe, we encourage readers of Acta Neurochirurgica eligible for participation to contribute to the ongoing survey. The final results from this survey will hopefully encourage the future work since the preliminary trends provided by Stienen and coworkers are alarming, and there may be reasons to modernize many residency programs to ensure high-quality training within the current framework of regulations. Solutions provided for this negative trend need to be balanced against the fact that we perform and learn better when we are awake.

\section{References}

1. Birkmeyer JD (2016) Surgical resident duty-hour rules-weighing the new evidence. N Engl J Med 374:783-784. https://doi.org/10. 1056/NEJMe1516572

2. Drazen JM (2004) Awake and informed. N Engl J Med 351:1884 1884. https://doi.org/10.1056/NEJMe048276

3. Eastridge BJ, Hamilton EC, O'Keefe GE, Rege RV, Valentine RJ, Jones DJ, Tesfay S, Thal ER (2003) Effect of sleep deprivation on the performance of simulated laparoscopic surgical skill. Am J Surg 186:169-174

4. Gerdes J, Kahol K, Smith M, Leyba MJ, Ferrara JJ (2008) Jack Barney award: the effect of fatigue on cognitive and psychomotor skills of trauma residents and attending surgeons. Am J Surg 196: 813-819; discussion 819-820. https://doi.org/10.1016/j.amjsurg. 2008.07.030

5. Lockley SW, Cronin JW, Evans EE, Cade BE, Lee CJ, Landrigan CP, Rothschild JM, Katz JT, Lilly CM, Stone PH, Aeschbach D, Czeisler CA (2004) Effect of reducing interns' weekly work hours on sleep and attentional failures. N Engl J Med 351:1829-1837. https://doi.org/10.1056/NEJMoa041404

6. Rajaram R, Chung JW, Cohen ME, Dahlke AR, Yang AD, Meeks JJ, Ko CY, Tarpley JL, Hoyt DB, Bilimoria KY (2015) Association of the 2011 ACGME resident duty hour reform with postoperative patient outcomes in surgical specialties. J Am Coll Surg 221:748757. https://doi.org/10.1016/j.jamcollsurg.2015.06.010

7. Rosenbaum L (2019) The not-my-problem problem. N Engl J Med 380:881-885. https://doi.org/10.1056/NEJMms1813431

8. Sherman IJ, Kretzer RM, Tamargo RJ (2006) Personal recollections of Walter E. Dandy and his brain team. J Neurosurg 105:487-493. https://doi.org/10.3171/jns.2006.105.3.487

9. Solheim O, Jakola AS, Gulati S, Johannesen TB (2012) Incidence and causes of perioperative mortality after primary surgery for intracranial tumors: a national, population-based study. J Neurosurg 116:825-834. https://doi.org/10.3171/2011.12.JNS11339

10. Stienen MN, Bartek Jr J, Czabanka MA, Freyschlag CF, Kolias A, Krieg SM, Moojen W, Renovanz M, Sampron N, Adib SD, Schubert GA, Demitriades AK, Ringel F, Regli L, Schaller K, Meling TR (2019) Neurosurgical procedures performed during residency in Europe - preliminary numbers and time trends. Acta Neurochir (Wien)

11. Volpp KG, Rosen AK, Rosenbaum PR, Romano PS, Even-Shoshan O, Wang Y, Bellini L, Behringer T, Silber JH (2007) Mortality among hospitalized Medicare beneficiaries in the first 2 years following ACGME resident duty hour reform. JAMA 298:975-983. https://doi.org/10.1001/jama.298.9.975

12. Williamson AM, Feyer AM (2000) Moderate sleep deprivation produces impairments in cognitive and motor performance equivalent to legally prescribed levels of alcohol intoxication. Occup Environ Med 57:649-655

Publisher's note Springer Nature remains neutral with regard to jurisdictional claims in published maps and institutional affiliations. 